\section{Capsulorrexis asistida mediante azul brillante (BBG) para cirujanos en formación}

\section{Brilliant blue G-assisted capsulorhexis: a good help for phacoemulsification surgeons in training}

La correcta realización de la capsulorrexis es un paso fundamental para el posterior buen desarrollo de la facoemulsificación, pero para los cirujanos en formación suele ser uno de los pasos que requiere una curva de aprendizaje mayor. Por este motivo, y porque en algunos casos en los que la retroiluminación dificulta la visualización óptima de la cápsula anterior proponemos la utilización del azul brillante $\mathrm{G}$ como una buena alternativa para la tinción de la capsula anterior así como del tunel de las incisiones realizadas (paracentesis e incisión principal) facilitando de este modo la introducción atraumática de los instrumentos y de la lente intraocular durante la cirugía (fig. 1).

Tanto el Trypan blue como el verde indocianina se han utilizado ampliamente con este fin, no demostrando una gran toxicidad in vivo aunque si in vitro (1). Una de las ventajas del uso del azul brillante $\mathrm{G}$, a parte de la buena visualización que proporciona, es que comparado con los anteriores ha demostrado ser menos tóxico in vitro (2).

«Brilliant Blue-G 250» (BBG) es distribuido por Sigma Aldrich en frascos de $25 \mathrm{gr}$ en polvo. Se almacena en individuales alícuotas de 25 mgr. Pre-

Fig. 1: Detalle de la tinción de la cápsula anterior durante la realización de la capsulorrexis y perfecta visualización de las incisiones realizadas. vio a la cirugía se diluye la alícuota en $30 \mathrm{ml}$ de suero fisiológico obteniendo así una concentración de $0,83 \mathrm{mg} / \mathrm{ml}$. Tras realizar la paracentesis inyectamos $0,5-1 \mathrm{ml}$ de BBG a través de un filtro milipore de $0,22 \mu$, y tras esperar 10 segundos lavamos la cámara anterior. La mínima concentración con la que hemos conseguido una tinción óptima de la cápsula anterior del cristalino es de $0,83 \mathrm{mg} / \mathrm{ml}$, siendo ineficaces concentraciones previas utilizadas en cirugía de vítreo retina (3) de $0,50 \mathrm{mg} / \mathrm{ml}$.

A pesar de utilizar una concentración ligeramente mayor, y tras realizar contaje endotelial sistemático pre y post cirugía, no hemos observado daño endotelial superior a la de una facoemulsificación normal (sin tinción) o tras introducir BBG a dosis inferiores (figs. 2).

Concluimos que el BBG es una alternativa eficaz y segura para la tinción de la cápsula anterior previa a la realización de la capsulorexis circular continua y facilita con su buena visualización el aprendizaje de esta fase quirúrgica del oftalmólogo en formación.

Udaondo $\mathrm{P}^{1}$, Díaz-Llopis $\mathrm{M}^{1,2}$, Salom $\mathrm{D}^{1}$, García-Delpech $\mathrm{S}^{1}$, Cervera $\mathrm{E}^{1,2}$

${ }^{1}$ Hospital General Universitario de Valencia.

${ }^{2}$ Facultad de Medicina, Universidad de Valencia. Servicio de Oftalmología Hospital General Universitario de Valencia Valencia. España E-mail: patyudaondo@hotmail.com

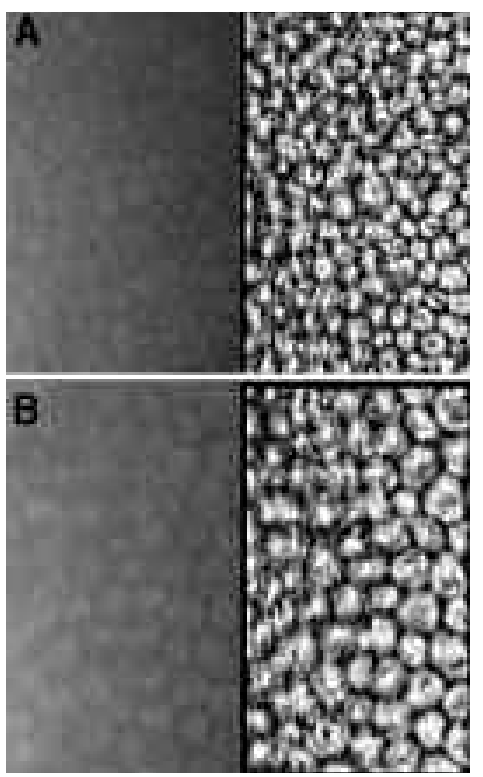

Fig. 2: Contaje endotelial pre y postcirugía (a y b) con uso de $B B G$. 


\section{BIBLIOGRAFÍA}

1. van Dooren BT, Beekhuis WH, Pels E. Biocompatibility of trypan blue with human corneal cells. Arch Ophthalmol 2004; 122: 736-742.

2. Hisatomi T, Enaida H, Matsumoto H, Kagimoto T, Ueno A, Hata $Y$, et al. Staining ability and biocompatibility of brilliant blue G: preclinical study of brillant blue $G$ as an adjunct for capsular staining. Arch Ophthalmol 2006; 124: 514-519.

3. Cervera E, Díaz-Llopis M, Salom D, Udaondo P, Amselem L. Azul brillante $G$ intravitreo para la tinción de la membrana limitante interna: una buena ayuda para el cirujano de vítreoretina en formación. Arch Soc Esp Oftalmol 2007; 82: 71-72. 